\title{
Model Kesuksesan Sistem Teknologi Informasi Delone \& McLean pada Sistem Informasi Pengelolaan Proyek
}

\author{
Nadya Safitri ${ }^{1, *}$ \\ ${ }^{1}$ Rekayasa Perangkat Lunak; Universitas Bina Insani; Jalan Siliwangi No 6 Rawa Panjang \\ Bekasi Timur,021- 82400924; e-mail: nadyasafitri@binainsani.ac.id. \\ * Korespondensi: e-mail: nadyasafitri@binainsani.ac.id
}

Diterima: 06 Mei 2020; Review: 12 Mei 2020; Disetujui: 30 Mei 2020

Cara sitasi: Safitri N. 2020. Model Kesuksesan Sistem Teknologi Informasi Delone \& McLean pada Sistem Informasi Pengelolaan Proyek. Informatics for Educators and Professionals. Vol 4(2): 173-182

\begin{abstract}
Abstrak: Kualitas Informasi dan penggunaan merupakan variabel yang terdapat pada model kesuksesan sistem informasi yang dikemukakan oleh Wiliam H.Delone dan Ephraim R.McLean pada tahun 1992. Penelitian ini bertujuan untuk melakukan pengukuran kesuksesan sistem informasi dengan melihat pengaruh dari kualitas informasi terhadap penggunaan. Tahapan yang dilakukan dari penelitian ini dimulai dengan membuat hipotesis, menyebar kuesioner kepada pengguna sistem informasi pengelola proyek, dan mengelola data kuesioner. Data kuesioner dikelola menggunakan metode SEM yang di bantu aplikasi Lisrel. Hasil penelitian ini adalah melihat kesusksesan sistem informasi berdasarkan pengaruh kualitas informasi terhadap penggunaan apakah hipotesis yang dirumuskan diterima atau ditolak, serta adanya rekomendasi yang diberikan terhadap sistem yang sedang berjalan berdasarkan hasil pengolahan data.
\end{abstract}

Kata kunci: kesuksesan sistem informasi, kualitas informasi, penggunaan, sistem pengelolaan proyek, SEM

Abstract: Information quality and usage are the variables contained in the information system success model proposed by William H. Delone and Ephraim R. McLean in 1992. This study aims to measure the success of information systems by looking at the effect of information quality on usage. Stages made from this study began by making hypotheses, distributing questionnaires to project management information system users, and managing questionnaire data. Questionnaire data is managed using SEM method which is assisted by the Lisrel application. The results of this study are looking at the success of the information system based on the influence of information quality on the use of whether the formulated hypothesis is accepted or rejected, as well as the recommendations given to the current system based on the results of data processing.

Keywords: information system success, information quality, usage, project management system, SEM

\section{Pendahuluan}

Sistem informasi telah diterapkan dalam berbagai bidang, seperti penerapan sistem informasi pada bidang transportasi, pendidikan, proyek, kesehatan, dan bidang-bidang lainnya. Salah satu yang cukup komplek adalah sistem informasi pengelolaan proyek. Sistem pengelolaan proyek merupakan sistem yang memproses data proyek dari mulai perencanaan, pengerjaan dan control yang dilakukan dalam sebuah proyek. Keluaran sistem ini memberikan informasi kepada sistem informasi seperti keuangan, pengadaan, sumber daya manusia, dan sistem produksi sebagai inputan dalam pengerjaan selanjutnya. Sehingga apa yang dihasilkan oleh sistem informasi pengelolaan proyek menjadi salah satu hal yang paling berpengaruh terhadap sistem lainnya. 
Kesuksesan penerapan sistem informasi merupakan salah satu harapan dari organisasi dengan harapan agar proses bisnis yang dilakukan oleh organisasi tersebut menjadi efektif dan efesien. Namun pada penggunaannya, sistem informasi selalu saja ada permasalahan, baik permasalahan yang timbul dari user maupun dari sistem. Maka dari itu untuk mengetahui apakah sistem informasi yang diterapkan telah sukses atau belum perlu dilakukan tahapan evaluasi atau pengukuran.

Pengukuran menjadi hal penting agar stake holder ataupun developer mengetahui apakah sistem informasi yang diterapkan dan digunakan sudah efektif dan efesien yang hasil akhir dari proses pengukuran ini dapat digunakan untuk proses pengembangan sistem informasi. Terdapat berbagai cara dan model yang dapat dilakukan untuk melakukan pengukuran sistem informasi namun pada penelitian ini pengukuran yang dilakukan menggunakan Model Kesuksesan Sistem Informasi Delone McLean.

Model Kesuksesan Sistem Informasi Delone McLean ini merupakan model yang dikemukakan oleh Wiliam H.Delone dan Ephraim R.McLean pada tahun 1992. Model ini mengambarkan keterhubungan antara variabel yang saling mempengaruhi. Adapun variabel nya yaitu system quality, information quality, use, user satisfaction, individual impact dan organizational impact. Model kesuksesan ini banyak digunakan untuk melakukan pengukuran dari implementasi sebuah sistem informasi. Namun berdasarkan beberapa penelitian masih terdapat kekurangan sehingga model ini di update pada tahun 2003 dengan penambahan beberapa variabel yaitu service quality, intention use, serta mengubah individual impact dan organizational impact menjadi net benefits[1], adapun model kesuksesan yang di update terlihat pada gambar 1. [2]

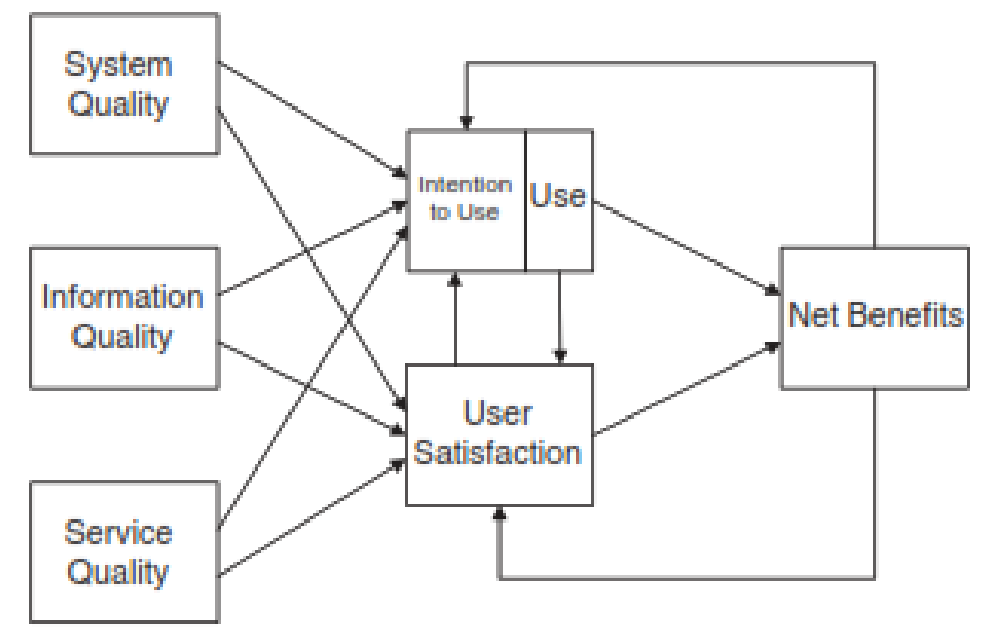

Sumber : Jogiyanto (2007)

Gambar 1. Updated DeLone and McLean IS Success Model (2003)

Berdasarkan penjelasan sebelumnya, maka penelitian ini akan berfokus mengukur kesuksesan sistem informasi dengan menggunakan 3 variabel yaitu kualitas informasi, kualitas sistem, dan penggunaan.

Kualitas informasi (information quality) merupakan salah satu pengukur kualitas luaran dari sistem informasi. Beberapa peneliti melakukan peneliti terhadap faktor-faktor untuk mengukur kualitas informasi salah satunya mengusulkan 39 item untuk mengukur kualitas informasi yang diantaranya akurasi informasi, ketepatan waktu keluaran, keandalan, kelengkapan, relevan, kekinian dan ketepatan [3]. Pada penelitian ini variabel teramati yang digunakan untuk mengukur kualitas informasi adalah kegunaan informasi, ketepatan waktu dan kelengkapan dari informasi.

Kualitas sistem merupakan variabel yang digunakan untuk mengukur kualitas sistem informasi. Beberapa peneliti melakukan penelitian terhadap faktor-faktor untuk mengukur kualitas sistem informasi mengusulkan beberapa variabel yang diantaranya adalah kenyamaan akses, keluwesan sistem, integritas sistem, waktu respon[3]. Pada penelitian ini variabel teramati yang digunakan untuk mengukur kualitas sistem adalah kemudahan penggunaan, kemudahan dipelajari dan integritas sistem. 
Penggunaan merupakan penggunaan keluaran suatu sistem informasi oleh penerima.Konsep penggunaan dari suatu sistem dapat dilihat dari beberapa perspektif, yaitu penggunaan nyata dan penggunaan persepsi. Beberapa penelitian mengusulkan beberapa faktor untuk mengukur penggunaan yaitu frekuensi penggunaan, motivasi untuk menggunakan, penggunaan SI mendukung pekerjaan, jumlah dari fitur-fitur DSS digunakan. Pada penelitian ini variabel teramati yang digunakan untuk mengukur penggunaan adalah frekuensi penggunaan, motivasi untuk menggunakan, serta penggunaan sistem informasi mendukung pekerjaan.

Berdasarkan penjelasan diatas maka dapat dirumuskan (1) Hipotesis 1 : Kualitas informasi berpengaruh terhadap penggunaan. Hubungan kualitas informasi terhadap penggunaan dapat dilihat dari kegunaan informasi dan ketepatan waktu (2) Hipotesis 2 : Kualitas Sistem berpengaruh terhadap penggunaan. Hubungan kualitas sistem terhadap penggunaan dapat dilihat dari kemudahan penggunaan, kemudahan dipelajari.

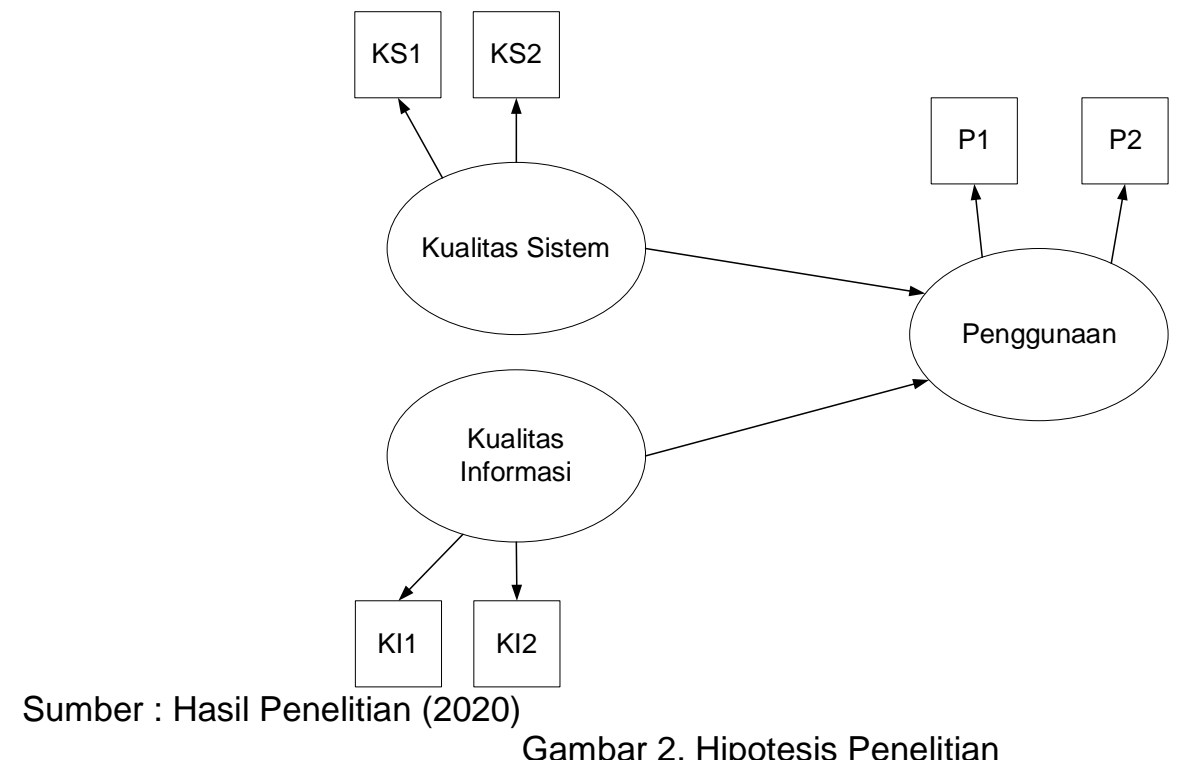

Gambar 2. Hipotesis Penelitian

\section{Metode Penelitian}

Penelitian ini menggunakan data primer yang diperoleh dengan melalui survey serta wawancara kepada responden dan pemberian kuesioner kepada pihak-pihak yang terkait dengan sistem informasi pengelolaan proyek. Populasi untuk penelitian ini adalah pengguna sistem informasi dari sistem pengelolaan projek yang ada pada suatu perusahaan. Pada perusahaan teramati terdapat 10 divisi yang menggunakan sistem ini dengan jumlah 100 orang pengguna. Berdasarkan hal tersebut selanjutnya dilakukan perhitungan jumlah sampel untuk penelitian. Terdapat dua cara yang digunakan untuk menentukan sampel, yaitu menentukan ukuran sampel dengan menggunakan rumus Isaac dan Michael, rumus ini diperuntukan untuk menghitung ukuran sampel yang jumlah populasinya diketahui.[4]

$$
s=\frac{\Lambda^{2} \cdot N \cdot P \cdot Q}{d^{2}(N-1)+\Lambda^{2} \cdot P Q}
$$

Berdasarkan persamaan diatas diketahui ukuran sampel dengan tingkat kesalahan $1 \%$ dari 100 yaitu 87 sampel, tingkat kesalahan 5\% dari 100 yaitu 78 sampel dan untuk tingkat kesalahan $10 \%$ yaitu 73 sampel. Sedangkan untuk perhitungan yang ke 2 yang dikemukakan Roscoe [5], sebaiknya ukuran sampel diantara 30 sampai dengan 500 elemen selain itu untuk penelitian multivariete ukuran sampel harus beberapa kali lebih besar (10 kali) dari jumlah variabel yang akan dianalisis.

Sedangkan untuk metode analisis data yang digunakan pada penelitian ini adalah metode Structural Equation Modeling (SEM) atau model persamaan struktural yang merupakan analisis multivariat yang digunakan untuk menganalisis hubungan antara variabel secara kompleks. Analisis data dengan menggunakan SEM berfungsi untuk menjelaskan secara 
menyeluruh hubungan antara variabel yang ada dalam penelitian. SEM digunakan untuk memeriksa dan membenarkan suatu model. Syarat urama menggunakan SEM adalah membangun suatu model hipotesis yang terdiri dari model struktural dan model pengukuran dalam bentuk diagram jalur. SEM merupakan sekumpulan teknik-teknik statistik yang memungkinkan pengujian sebuah rangkaian hubungan secara simultan[6].

SEM memiliki karakteristik yang terdiri dari dua model yaitu model struktural dan model pengukuran. Ada dua jenis variabel dalam SEM yaitu variabel laten dan variabel teramati[7]. Variabel laten merupakan konsep abstrak, sebagai contoh : perilaku orang, sikap, perasaan dan motivasi. Variabel laten ini hanya diamati secara tidak langsung dan tidak sempurna melalui efeknya pada variabel teramati. Variabel laten terdiri dari dua jenis yang dibedakan berdasarkan keikutsertaannya sebagai variabel terikat pada persamaan-persamaan dalam model yaitu variabel eksogen dan variabel endogen. Variabel eksogen selalu muncul sebagai variabel bebas pada semua persamaan yang ada dalam model. Sedangkan variabel endogen merupakan variabel terikat pada paling sedikit satu persamaan dalam model,meskipun disemua persamaan sisanya variabel adalah variabel bebas. Sedangkan Variabel teramati (observed variable) atau variabel terukur (meansured variable, disingkat MV) adalah variabel yang dapat diamati dan dapat diukur secara empiris dan sering disebut sebagai indikator. Variabel teramati merupakan efek atau ukuran dari variabel laten. Pada metode survei dengan menggunakan kuesioner, setiap pertanyaan pada kuesioner mewakili sebuah variabel teramati, sehingga jika sebuah kuesioner mempunyai 50 pertanyaan, maka akan ada 50 variabel teramati. Variabel teramati yang berkaitan atau merupakan efek dari variabel laten eksogen (ksi) diberi notasi matematik dengan label $X$, sedangkan yang berkaitan dengan variabel laten endogen (eta) diberi label Y. Simbol diagram lintasan dari variabel teramati adalah bujur sangkat atau kotak atau empat persegi panjang.

Metode analisis data SEM memiliki model yaitu model struktural dan model pengukuran. Model struktural menggambarkan hubungan-hubungan yang ada di antara variabel-variabel laten. Hubungan-hubungan ini umumnya linier, meskipun perluasan SEM memungkinkan untuk mengikutsertakan hubungan non-linier. Sebuah hubungan diantara variabel-variabel laten serupa dengan sebuah persamaan regresi linier diantara variabel-variabel laten. Sedangkan Model pengukuran menggambarkan hubungan antara variabel laten dengan variabel-variabel teramati melalui model pengukuran yang berbentuk analisis faktor dan banyak digunakan dipsikometri dan sosiometri.

Secara umum tahapannya terdiri dari 5 tahap (1) Spesifikasi model (specification mode), tahapan ini berkaitan dengan pembentukan model awal persamaan struktural, sebelum dilakukan estimasi.[8] Model awal ini diformulasikan berdasarkan suatu teori atau penelitian sebelumnya; (2) Identifikasi (identification), tahapan ini berkaitan dengan pengkajian tentang kemungkinan diperolehnya nilai yang unik untuk setiap parameter yang ada didalam model dan kemungkinan persamaan simultan tidak ada solusinya; (3) Estimasi (estimation),tahapan ini berkaitan dengan estimasi terhadap model untuk menghasilakn nilai-nilai parameter dengan menggunakan salah satu metode estimasi yang tersedia. Pilih metode estimasi yang digunakan seringkali ditentukan berdasarkan karakteristik dari variabel-variabel yang dianalisis; (4) Uji kecocokan (testing fit), tahapan estimasi diatas menghasilkan solusi yang berisi nilai akhir dari parameter-parameter yang diestimasi. Dalam tahapan ini, kita akan memeriksa tingkat kecocokan antara data dengan model, validitas dan reliabilitas model pengukuran dan signifikansi koefisien-koefisien dari model struktural. Evaluasi terhadap tingkat kecocokan data dengan model dilakukan melalui beberapa tahapan, yaitu kecocokan keseluruhan model, kecocokan model pengukuran dan Kecocokan model struktural; (5) Respesifikasi (respecification), tahap ini berkaitan dengan respesifikasi model yang berdasarkan atas hasil uji kecocokan tahap sebelumnya. Respesifikasi model dilakukan untuk memperbaiki kecocokan model terhadap data. Untuk melakukan hal ini dapat memanfaatkan informasi pada indek modifikasi (modification indices) yang ada pada print output keluaran dari perangkat lunak LISREL 8.8[9]. Ada dua saran dalam melakukan indek modifikasi, yaitu penambahan lintasan antara var. laten var.teramati dan penambahan kovariasi diantara dua kesalahan. Adapun flowchat dari tahapan SEM terdapat pada gambar 3. 


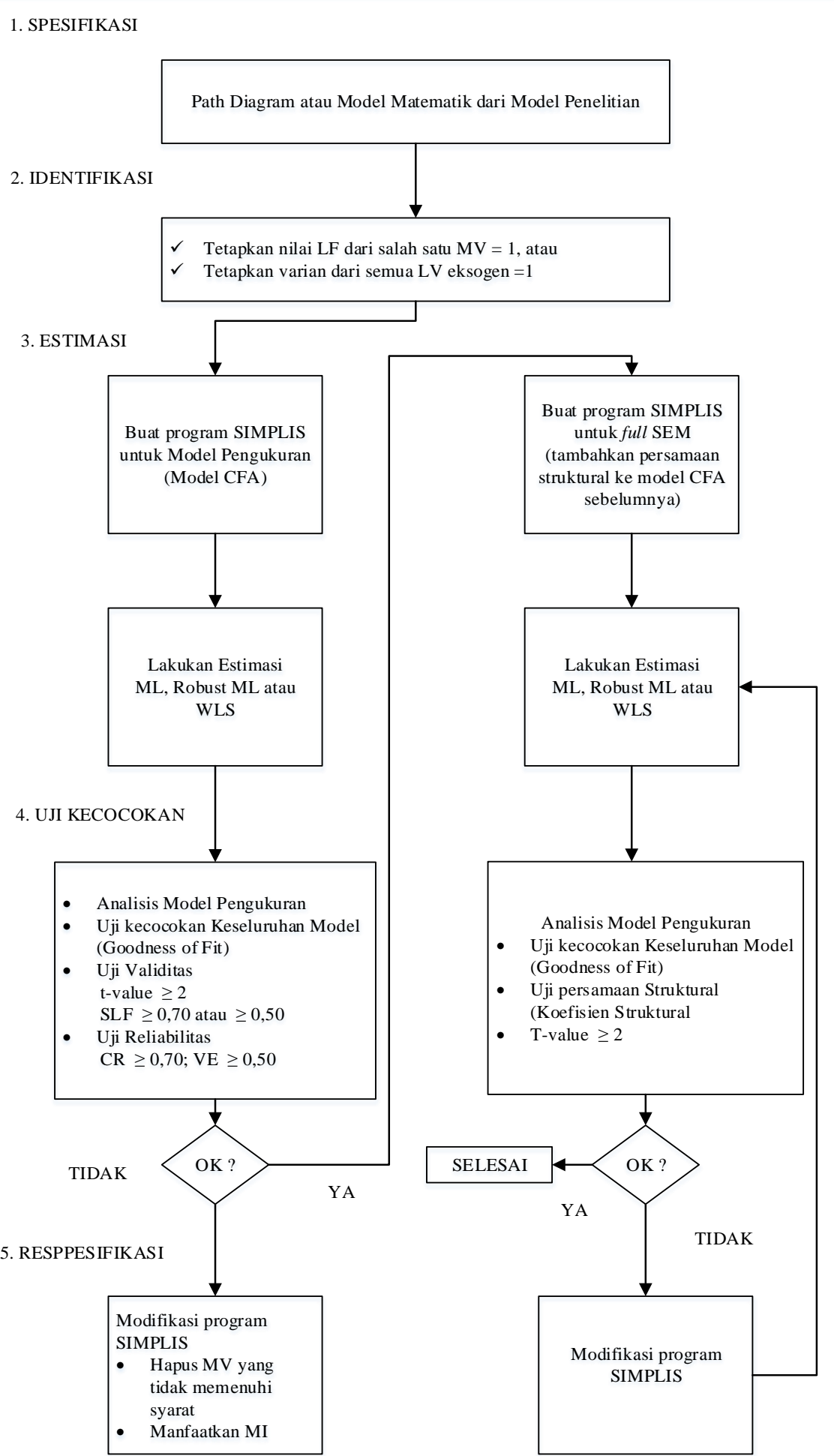

- LF : Loading Factor

- SLF : Standardized Loading Factor, MV: Measured Variables, LV : Latent Variables

- CR : Construct Reliability, VE : Varience Extracted; CFA : Confirmatory Factor Analysis

- ML : Maximum Likelihood; WLS : Weighted Least Square; Ml : Modification Index 


\section{Hasil dan Pembahasan}

Data yang sebelumnya dikumpulkan, selanjutnya diolah dengan menggunakan metode Structural Equation Modeling (SEM) yang dibantu dengan aplikasi Lisrel 8.8 dengan menggunakan sintak SIMPLIS.

Tahapan pertama yang dilakukan adalah spesifikasi model. Tahapan ini mendefinisikan variabel-variabel laten, variabel teramati, hubungan antara variabel laten dan variabel teramati, hubungan kausal diantara variabel-variabel laten, serta menggambarkan path diagram.

Tahapan selanjutnya yaitu identifikasi. Tahapan ini model harus memiliki nilai yang unik sehingga dapat diestimasi pada tahap selanjutnya. Seperti yang dijelaskan Wijanto yang dimaksud dengan nilai yang unik adalah model yang over-identified atau yang mempunyai degree of freedom (df) positif, maka dapat dilanjutkan kedalam tahapan selanjutnya. Dalam model penelitian ini mempunyai degree of freedom (df) positif, maka dapat dilanjutkan kedalam tahap selanjutnya[7]. Degree of fredom adalah jumlah data yang diketahui dikuragi jumlah parameter yang diestimasi. Jadi Degree of fredom $=19-13=6>0$, dan ini berarti bahwa model yang dispesifikasikan adalah over-identified.

\section{Estimasi}

Model yang telah di identifikasi selanjutnya diestimasi. Tahapan ini mulai dibuat program SIMPLIS. Hasil estimasi yang perlu diperhatikan yaitu adanya offending estimates (nilai-nilai estimasi yang melebihi batas yang dapat diterima). Beberapa offending estimates yang sering ditemui adalah (1) Negative error variances atau nonsignificant error variances untuk konstrukkontruk yang ada; (2) Standardized coefficient melebihi atau sangat dekat dengan 1; (3) Standard errors yang berhubungan dengan koefisien-koefisien yang diestimasi mempunyai nilai sangat besar. Gambar 4 ini merupakan gambar path diagram yang dihasilkan dari hasil estimasi yang dilakukan sebelumnya. Sedangkan gambar 4 merupakan output yang dihasilkan pada saat program dijalankan.

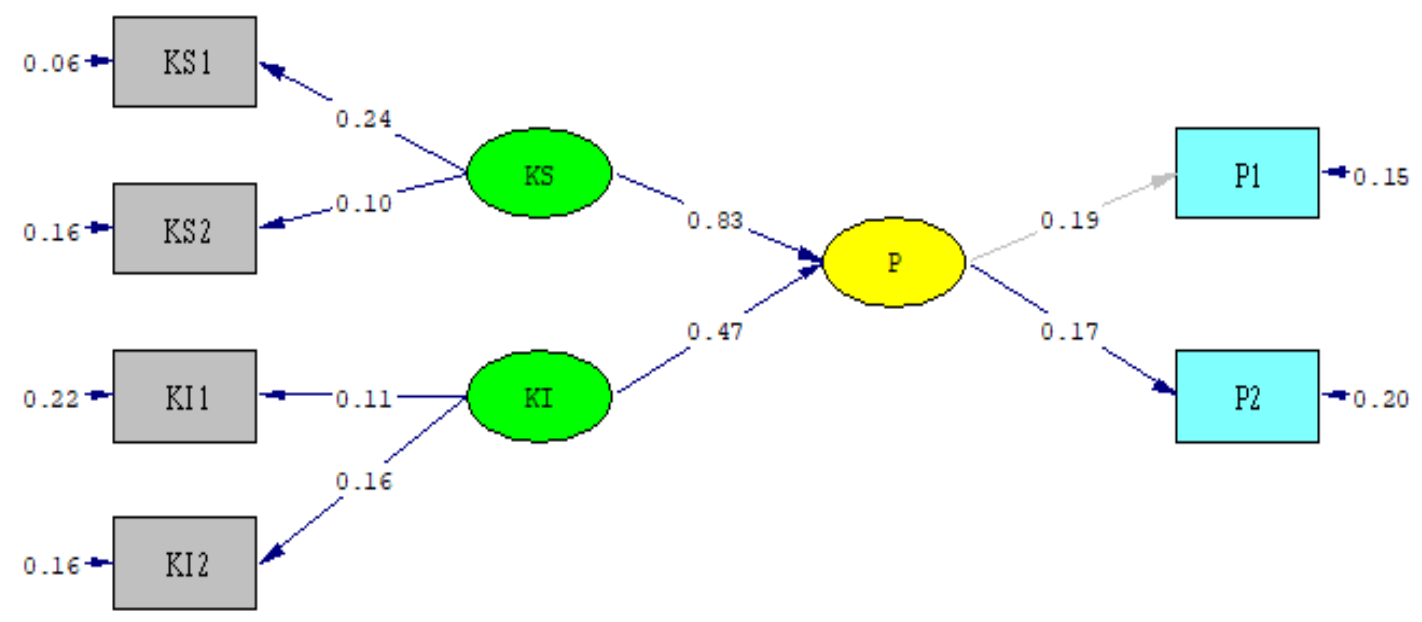

Chi-Square=30.71, df=6, P-value=0.00003, RMSEA $=0.141$

Sumber : Hasil Penelitian (2020)

Gambar 2 Path Diagram pada Lisrel 8.8

Berdasarkan hasil running pada Lisrel 8.8 terdapat pula hasil yang digunakan untuk menguji kecocokan model yang terdapat pada tabel 1 dan akan di jelaskan secara rinci pada tabel 2.

Tabel 1 Goodness of Fit Statistics pada Lisrel 8.8

\footnotetext{
Result

Goodness of Fit Statistics

Degrees of Freedom $=6$

Minimum Fit Function Chi-Square $=6.23(P=0.40)$

Normal Theory Weighted Least Squares Chi-Square $=5.61(P=0.47)$

Chi-Square Difference with 0 Degree of Freedom $=25.10(P=1.00)$

Estimated Non-centrality Parameter (NCP) $=0.0$

90 Percent Confidence Interval for NCP $=(0.0 ; 9.41)$

Minimum Fit Function Value $=0.16$

Population Discrepancy Function Value $(F 0)=0.0$
} 
90 Percent Confidence Interval for F0 $=(0.0 ; 0.25)$

Root Mean Square Error of Approximation (RMSEA) $=0.0$

90 Percent Confidence Interval for RMSEA $=(0.0 ; 0.20)$

P-Value for Test of Close Fit $($ RMSEA < 0.05) $=0.53$

Expected Cross-Validation Index $(\mathrm{ECVI})=0.95$

90 Percent Confidence Interval for ECVI $=(0.95 ; 1.20)$

ECVI for Saturated Model $=1.11$

ECVI for Independence Model $=0.88$

Chi-Square for Independence Model with 15 Degrees of Freedom $=21.48$

Independence $\mathrm{AIC}=33.48$

Model AIC $=35.61$

Saturated $\mathrm{AIC}=42.00$

Independence CAIC $=49.46$

Model CAIC $=75.56$

Saturated CAIC $=97.93$

Normed Fit Index $(\mathrm{NFI})=0.71$

Non-Normed Fit Index $(\mathrm{NNFI})=0.91$

Parsimony Normed Fit Index $(\mathrm{PNFI})=0.28$

Comparative Fit Index $(\mathrm{CFI})=0.96$

Incremental Fit Index (IFI) $=0.99$

Relative Fit Index $(\mathrm{RFI})=0.27$

Critical N $(\mathrm{CN})=103.53$

Root Mean Square Residual $(\mathrm{RMR})=0.015$

Standardized RMR $=0.073$

Goodness of Fit Index (GFI) $=0.95$

Adjusted Goodness of Fit Index (AGFI) $=0.84$

Parsimony Goodness of Fit Index (PGFI) $=0.27$

Sumber : Hasil Penelitian (2020)

\section{Uji Kecocokan Model}

Tahapan uji kecocokan model ini ada dua model yang akan diuji yaitu model keseluruhan, model pengukuran dan model struktural. Adapun penjelasan dari masing-masing pengujian akan dijelaskan pada sub-bab selanjutnya.

Tahap pertama uji kecocokan ini ditujukan untuk mengevaluasi secara umum derajat kecocokan atau Goodness Of Fit (GOF) antara data dan model. Menguji kecocokan model keseluruhan ini dikelompokan menjadi 3 bagian yaitu absolute fit measures (ukuran kesosokan absolut), incremental fit measures (ukuran kecocokan inkremental), dan parsimonious fit measures (ukuran kecocokan parsimoni). Tabel 1 merupakan hasil uji kecocokan keseluruhan model yang telah dilakukan sebelumnya dengan menggunakan LISREL.

\begin{tabular}{|c|c|c|c|}
\hline Ukuran GOF & $\begin{array}{l}\text { Target Tingkat } \\
\text { Kecocokan }\end{array}$ & $\begin{array}{l}\text { Hasil Estimasi } \\
\text { Model Awal }\end{array}$ & Tingkat Kecocokan \\
\hline $\begin{array}{l}\text { Chi-Square } \\
P\end{array}$ & $\begin{array}{l}\text { Nilai yang kecil } \\
p>0,05\end{array}$ & $\begin{array}{l}X^{2}=5.61 \\
(P=0.47)\end{array}$ & Baik \\
\hline $\begin{array}{l}\mathrm{NCP} \\
\text { Interval }\end{array}$ & $\begin{array}{c}\text { Nilai yang Kecil } \\
\text { Interval yang sempit }\end{array}$ & $\begin{array}{c}0.0 \\
(0.0 ; 9.41)\end{array}$ & Baik \\
\hline RMSEA & RMSEA $\leq 0,08$ & 0.0 & \\
\hline$P$ (Close fit) & $p \geq 0,50$ & 0.53 & Baik \\
\hline ECVI & $\begin{array}{l}\text { Nilai yang kecil dan dekat } \\
\text { dengan ECVI saturared }\end{array}$ & $\begin{array}{l}\mathrm{M}^{*}=0.95 \\
\mathrm{~S}^{*}=1.11 \\
\mathrm{I}^{*}=0.88\end{array}$ & Baik \\
\hline AIC & $\begin{array}{l}\text { Nilai yang kecil dan dekat } \\
\text { dengan AIC saturated }\end{array}$ & $\begin{aligned} \mathrm{M}^{*} & =35.61 \\
\mathrm{~S}^{*} & =42.00 \\
\mathrm{I}^{*} & =33.48\end{aligned}$ & Baik \\
\hline CAIC & $\begin{array}{l}\text { Nilai yang kecil dan dekat } \\
\text { dengan CAIC saturated }\end{array}$ & $\begin{array}{l}\mathrm{M}^{\star}=75.56 \\
\mathrm{~S}^{*}=97.93 \\
\mathrm{I}^{*}=49.46\end{array}$ & Kurang Baik \\
\hline $\mathrm{NFI}$ & $\mathrm{NFI} \geq 0,09$ & 0.71 & Baik \\
\hline NNFI & $\mathrm{NNFI} \geq 0,90$ & 0.91 & Baik \\
\hline CFI & $\mathrm{CFI} \geq 0,90$ & 0.96 & Baik \\
\hline IFI & $\mathrm{IFI} \geq 0,90$ & 0.99 & Baik \\
\hline RFI & $\mathrm{RFI} \geq 0,09$ & 0.27 & Baik \\
\hline $\mathrm{CN}$ & $\mathrm{CN} \geq 200$ & 103.53 & Kurang baik \\
\hline
\end{tabular}




\begin{tabular}{lccc}
\hline Ukuran GOF & $\begin{array}{c}\text { Target Tingkat } \\
\text { Kecocokan }\end{array}$ & $\begin{array}{c}\text { Hasil Estimasi } \\
\text { Model Awal }\end{array}$ & Tingkat Kecocokan \\
\hline RMR & Standardized RMR $\leq 200$ & 0.015 & Kurang baik \\
\hline GFI & GFI $\geq 0,90$ & 0.95 & Baik \\
\hline AGFI & AGFI $\geq 0,90$ & 0.84 & Kurang baik \\
\hline
\end{tabular}

Sumber: Hasil Penelitian (2020)

Langkah selanjutnya setelah uji kecocokan keseluruhan model dan data adalah melakukan uji kecocokan model pengukuran. Pengujian ini dilakukan terhadap hubungan antara variabel laten dengan variabel teramati, pengujian ini melalui dua tahapan yaitu uji validitas dan uji reliabilitas. Uji validitas ini dilakukan bertujuan untuk melihat gambaran tentang kevalidan tiap indikator instrument penelitian/kuesioner. Variabel teramati atau indikator dikatakan mempunyai validitas yang baik terhadap konstruk atau variabel latennya, jika nilai t muatan faktornya (loading factors) $\geq 1.96$ atau untuk praktisnya $\geq 2$ dan muatan faktor standarnya (standardized loading factors) $\geq 0.5$.

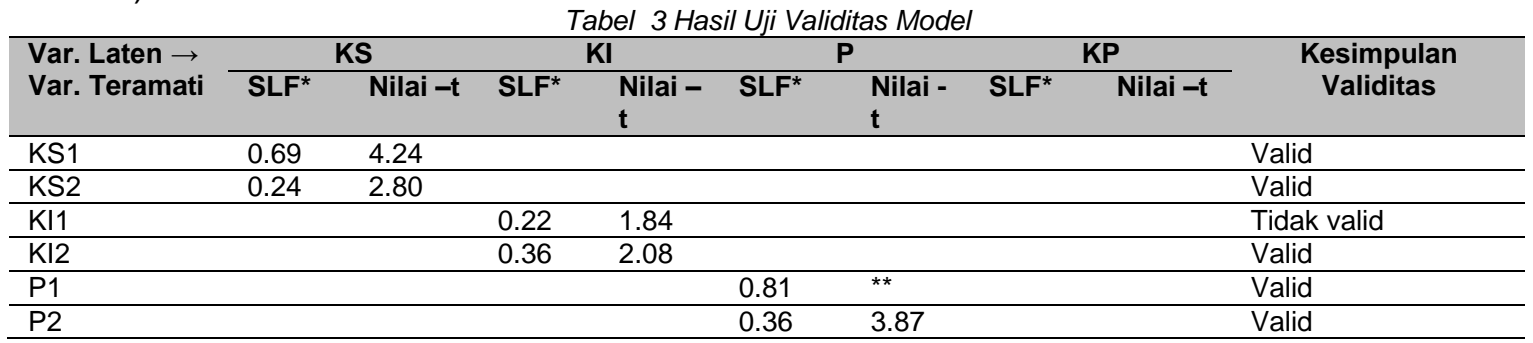

${ }^{*}$ SLF $=$ Standardized Loading Factors. Target SLF $\geq 0,5$

${ }^{* *}=$ Ditetapkan secara default oleh LISREL, nilai -t tidak di estimasi. Target nilai $\mathrm{t} \geq 2$

Sumber: Hasil Penelitian (2020)

Uji reliabilitas dilakukan untuk melihat konsistensi suatu pengukuran. Reliabilitas tinggi menunjukan bahwa indikator-indikator mempunyai konsistensi tinggi dalam mengukur konstruk latennya. Sebuah konstruk mempunyai reliabilitas yang baik jika nilai construct reliability (CR)nya $\geq 0,70$ dan nilai variance extracted (VE)-nya $\geq 0,50[10]$. Adapun rumus dari CR dan VE terdapat pada rumus 2 dan 3[11]

$$
\begin{aligned}
& \text { Construct Reliability }=\frac{\left(\sum \text { Standardized Loading }\right)^{2}}{\left(\sum \text { Standardized Loading }\right)^{2}+\sum e j} \\
& \text { Variance Extract }=\frac{\sum \text { Standardized Loading }{ }^{2}}{\sum \text { Standardized Loading }{ }^{2}+\sum e j}
\end{aligned}
$$

Tabel 4 dibawah ini merupakan hasil perhitungan CR dan VE yang memperlihatkan hasil uji reliabilitas yang telah dilakukan.

\begin{tabular}{cccc}
\multicolumn{5}{c}{ Tabel 4 Hasil Uji Reliabilitas Model } \\
\hline Variabel & CR & VE & Kesimpulan Reliabilitas \\
\hline KS & $0,37 \geq 0,70$ & $0,27 \geq 0,50$ & Tidak Reliabel \\
\hline KI & $0,156 \geq 0,70$ & $0,089 \geq 0,50$ & Tidak Reliabel \\
\hline P & $0,28 \geq 0,70$ & $0,165 \geq 0,50$ & Tidak Reliabel
\end{tabular}

Tahap ini termasuk dalam analisis model struktural, dalam analisis model struktural yang perlu diperhatikan adalah nilai-t karena nilai ini akan mempengaruhi hipotesis penelitian. Jika nilai-t $>$ 1,96 atau praktisnya adalah 2, maka hipotesis diterima,namun jika nilai-t $<1,96$ maka hipotesis ditolak. Gambar 5 merupakan gambaran hipotesis yang telah dilakukan pengujian berdasarkan tahapan yang ada pada SEM. 


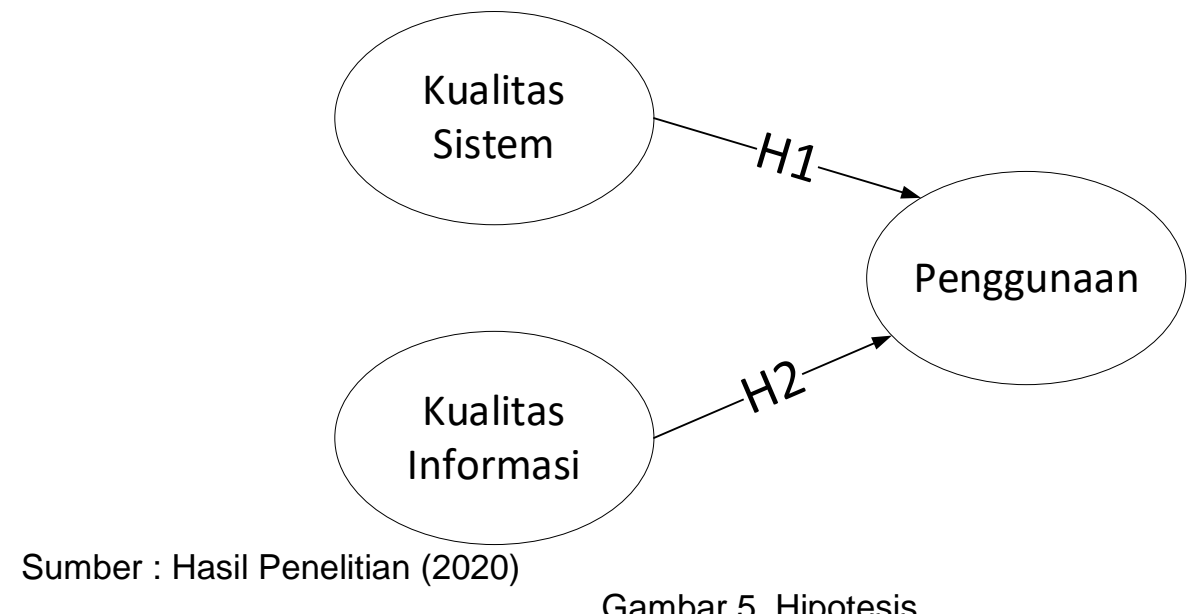

Tabel 5 ini merupakan tabel pengujian dari hipotesis yang diusulkan pada penelitian ini.

\begin{tabular}{cccc} 
& Tabel 5 Uji Hipotesis & Nilai $-\mathbf{t}$ & Kesimpulan \\
\hline Hipotesis & Path & 0.50 & Ditolak \\
\hline 1 & $\mathrm{KS} \rightarrow \mathrm{P}$ & 0.28 & Ditolak \\
\hline 2 & $\mathrm{KI} \rightarrow \mathrm{P}$ & &
\end{tabular}

Sumber : Hasil Penelitian (2020)

Hipotesis $1(\mathrm{H} 1)$ : Kualitas Sistem mempengaruhi Penggunaan. Sesuai dengan hasil uji hipotesis pada tabel 4, didapatkan hasil nilai -t sebesar 0,50 . Hal ini menunjukan bahwa koefisiensinya signifikan, yaitu $\geq 1,96$ sehingga hipotesis 1 ditolak. Dapat dikatakan bahwa kualitas sistem berpengaruh negatif terhadap penggunaan sistem informasi pengelolaan proyek.

Hipotesis $2(\mathrm{H} 2)$ : Kualitas Informasi mempengaruhi Penggunaan. Sesuai dengan hasil uji hipotesis pada tabel 5.4, didapatkan hasil nilai -t sebesar 0,28. Hal ini menunjukan bahwa koefisiensinya tidak signifikan, yaitu $<1,96$ sehingga hipotesis 2 ditolak. Dapat dikatakan kualitas informasi berpengaruh negatif terhadap penggunaan.

\section{Kesimpulan}

Berdasarkan penelitian yang dilakukan, dapat disimpulkan bahwa hipotesis yang diajukan dalam penelitian ini ditolak. Hal ini disebabkan karena kualitas informasi yang dilihat dari variabel kegunaan informasi serta variabel ketepatan waktu yang dihasilkan dari sistem informasi pengelolaan proyek tidak memiliki pengaruh positif terhadap penggunaan. Serta kualitas sistem yang dilihat dari variabel kemudahan penggunaan dan variabel kemudahan dipelajari tidak memiliki pengaruh poditif terhadap penggunaan. Berdasarkan hal tersebut maka bisa disimpulkan bahwa penerapan sistem pengelolaan proyek belum dinyatakan sukses penerapannya. Diharapkan pada penelitian selanjutnya bisa mengimplentasikan dengan jumlah populasi yang berbeda dan studi kasus yang berbeda sehingga hipotesis dapat teruji.

\section{Referensi}

[1] Jogiyanto, Model Kesuksesan Sistem Teknologi Informasi. Yogyakarta: Andi, 2007.

[2] J. M. Hudin And D. Riana, "Kajian Model Kesuksesan Sistem Informasi Delone \& Mclean Pada Pengguna Sistem Informasi Akuntansi Accurate Di Kota Sukabumi," J. Sist. Inf., Vol. 12, No. 1, P. 1, 2016, Doi: 10.21609/Jsi.V12i1.444.

[3] J. E. Bailey, "Development Of A Tool For Measuring And Analyzing Computer User Satisfaction," Manage. Sci., Vol. 29, No. 5, Pp. 519-637, 1983, Doi: Https://Doi.Org/10.1287/Mnsc.29.5.530.

[4] Sugiyono, Metodologi Penelitian Pendidikan (Pendidikan Kualitatif, Kuantitatif, Dan $R \& D)$. Bandung: Alfabeta, 2010.

[5] John Roscoe, "Fundamental Research Statistic For The Behavioral Science," 1975.

[6] Ramadiani, "Sem Dan Lisrel Untuk Analisis Multivariate," J. Sist. Inf., Vol. 2, No. 1, Pp. 179-188, 2010. 
[7] S. H. Wijanto, Structural Equation Modeling Dengan Lisrel 8.8. Yogyakarta: Graha IImu, 2008.

[8] I. Gozali, Structural Equation Modeling Metode Alternatif Dengan Partial Least Square Pls, 3rd Ed. Semarang: Badan Penerbit Universitas Diponogoro.

[9] Y. Yuliasia, I. Santoso, And A. Hidayat, "Analisis Variabel Yang Mempengaruhi Keinginan Berpindah (Turnover Intention) Dengan Structural Equation Modeling (Sem) (Studi Kasus Pt Wonokoyo Jaya Corporindo, Pasuruan)," Teknol. Pertan., Vol. 13, No. 1, Pp. 61-66, 2012.

[10] J. Hair, Multivariate Data Analysis, 5th Ed. New Jersey: Prentice Hall, 1998.

[11] R. D. Sumantri, "Analysis Of Customer Relationship Management (Crm) Influence On Satisfaction And Its Impact On Consumer Loyalty Of Pt. Raharja Duta Solusindo," Dinasti Int. J. Educ. Manag. Soc. Sci., Vol. 1, No. 4, Pp. 437-447, 2020, Doi: Https://Doi.Org/10.31933/Dijemss.V1i4. 